\title{
Pleurabrade: A Spiral Brush for Mechanical Pleurodesis and a Review of the Literature
}

\author{
John S. Young ${ }^{1}$ Desiree A. Steimer ${ }^{1}$ Emily Polhemus ${ }^{1} \quad$ Raphael Bueno $^{1}$ \\ 1 Division of Thoracic Surgery, Brigham and Women's Hospital, \\ Boston, Massachusetts, United States \\ Thorac Cardiovasc Surg Rep 2021;10:e36-e38. \\ Address for correspondence John Young, MD, Department of \\ Thoracic Surgery, Brigham and Women's Hospital, 75 Francis Street, \\ Boston, MA 02115, United States \\ (e-mail: jsyoungthoracic@gmail.com).
}

\begin{abstract}
Background While the optimal treatment for primary spontaneous pneumothorax remains unclear, mechanical pleurodesis is a well-established treatment. The Pleurabrade is a spiral brush designed for mechanical pleurodesis during thoracoscopy. We present two patients who underwent mechanical pleurodesis with the Pleurabrade.

Keywords

- mechanical pleurodesis

- spontaneous pneumothorax

- pleural abrasion

Case Description Two patients with spontaneous pneumothorax underwent operative intervention including mechanical pleurodesis with the Pleurabrade. Chest tubes were removed within 48 hours postoperatively and they were discharged home. Both patients remain recurrence free at 11 and 22 months, respectively.

Conclusion While further testing is needed, these case reports and operative video highlight the Pleurabrade as an efficient device for thoracoscopic mechanical pleurodesis.
\end{abstract}

\section{Introduction}

Primary spontaneous pneumothorax is frequently seen in young, tall men and is typically the result of rupture of apical blebs. ${ }^{1}$ Recurrence of an ipsilateral spontaneous pneumothorax remains relatively low, around $25 \%$, so many clinicians will manage an initial occurrence less invasively (observation, needle decompression, or tube thoracostomy). ${ }^{2,3}$ However, recurrence risk increases with subsequent events. Thus, operative intervention is typically reserved for a recurrence or those cases with high-risk features such as tension pneumothorax, or occupational or recreational risks (pilots or scuba divers). ${ }^{2}$ Surgical options include mechanical pleurodesis with bleb resection, or chemical pleurodesis; however, the optimal means of preventing recurrence remains unclear.

Pleural abrasion is an accepted means of mechanical pleurodesis and is thought to have a lower rate of bleeding complications compared with pleurectomy, which is usually reserved for recurrence after a surgical treatment for pneumothorax. ${ }^{4}$ Maintaining the pleura also makes reoperation in the chest easier compared with pleurectomy. ${ }^{5}$ Many surgeons will abrade the pleura with an electrocautery scratch pad or a sponge. ${ }^{6}$

received

July 20,2020

accepted after revision

November 16, 2020
These have a small point of contact with the pleura and are therefore somewhat more cumbersome, time consuming, and are at risk of becoming a retained foreign body. ${ }^{6}$ We report herein two patients who successfully underwent mechanical pleurodesis with the Pleurabrade (Butterfield Technologies, Portland, Maine, United States), an instrument with nylon bristle brushes specifically designed for mechanical pleurodesis. The Pleurabrade (Butterfield Technologies) overcomes some of the limitations of the other techniques of pleural abrasion.

\section{Case Presentations}

\section{Case 1}

An otherwise healthy 24-year-old man presented at an outside hospital with 2 days of right-sided chest pain and dyspnea. A chest X-ray showed a moderate to large right pneumothorax and a small associated effusion. A thoracic vent was placed in the emergency room and he was discharged home with the thoracic vent in place. He presented in our clinic 6 days later and repeat imaging showed increased size of his pneumothorax. Based on our recommendation, the patient agreed to operative intervention. He was taken to the operating room

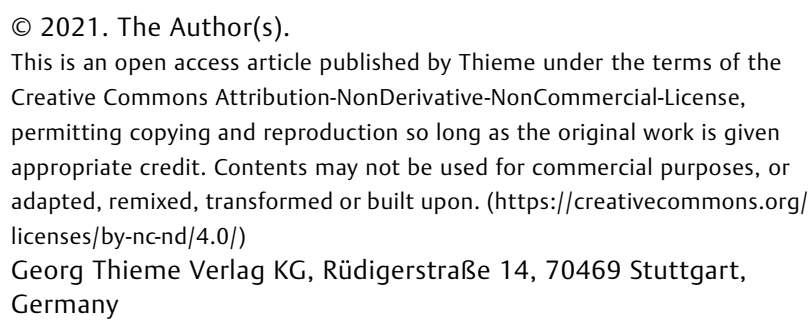


and underwent a right video-assisted thoracoscopic surgery (VATS) where a ruptured bleb was identified in the apex and resected using a stapler. The Pleurabrade (Butterfield Technologies) was used to perform a mechanical pleurodesis. After 48 hours of $-20 \mathrm{~cm} \mathrm{H}_{2} \mathrm{O}$ of suction, he tolerated a water seal trial and his chest tube was removed. He was discharged on postoperative day 3 . He remains without recurrence at 22 months at the time of reporting.

\section{Case 2}

A 25-year-old man with a history of a right spontaneous pneumothorax managed with a tube thoracostomy 3 months prior presented to an outside hospital with acute left-sided chest pain and dyspnea. A chest X-ray showed a left apical pneumothorax and he was transferred to our institution for management. A left pleural $14 \mathrm{Fr}$ pigtail was placed on arrival. He underwent a left VATS; multiple apical blebs were seen and surgically resected. A partial and apical pleurectomy was performed, and the remainder of the pleura was abraded with the Pleurabrade (Butterfield Technologies). Postoperatively, his chest tube was removed after 48 hours of suction and a successful water seal trial. He was discharged on postoperative day 2 and remains without recurrence at 11 months of follow-up.

\section{Discussion}

Primary spontaneous pneumothorax is a subset of spontaneous pneumothorax and occurs in patients without prior lung disease and typically affects tall thin males between the ages of 10 and 30 years. ${ }^{1}$ It has an incidence of 18 to $28 / 100,000$ cases per year for men and 1.6 to $6 / 100,000$ cases for women. ${ }^{1}$ The optimal management of primary spontaneous pneumothorax remains controversial. For initial occurrences, management options include observation, aspiration, tube drainage, chemical pleurodesis, or mechanical pleurodesis with wedge resection of culprit lesions. ${ }^{2,3}$ The option chosen depends on patient as well as clinician factors and preferences. ${ }^{2}$ Large blebs, for instance, may be a reason to operate with a VATS wedge resection and pleurodesis on an initial presentation. ${ }^{7}$ Given the increasing rates of recurrence with each subsequent episode, many surgeons elect to perform a pleurodesis at a second occurrence. $^{2}$

Pleurodesis aims to obliterate the pleural space by producing extensive adhesion of the visceral and parietal pleura. ${ }^{8}$ While a direct apposition between the two pleural surfaces is necessary, the inflammatory process involving mesothelial cell release of inflammatory mediators, production of fibrin adhesions, and recruitment of fibroblasts and collagen production is critical for a successful pleurodesis. ${ }^{8}$ Techniques for achieving pleurodesis include both mechanical (either by pleural abrasion or parietal pleurectomy) or pleurodesis with a sclerosing agent.

Whether there is a benefit to chemical or mechanical pleurodesis with bleb resection is an area of debate. A 2014 randomized controlled study suggested that the addition of a mechanical pleurodesis did not significantly decrease the risk of recurrence but did add additional bleeding and postoperative drainage. ${ }^{9}$ The report, however, does not clarify which patients were brought to the operating room at an initial versus recurrent spontaneous pneumothorax. ${ }^{9}$ Several other studies have examined this issue and while a 2019 systemic review and meta-analysis suggested that following bullectomy, chemical pleurodesis is superior to mechanical pleurodesis in reducing hospital stay and recurrence rate, they acknowledged that more directed randomized controlled trials with a longer follow-up period are necessary. ${ }^{10}$ Thoracoscopic pleural abrasion has been established as a safe means of mechanical pleurodesis, ${ }^{11}$ although some argue that it has a higher recurrence rate than pleurectomy or chemical pleurodesis. ${ }^{4,10}$ One hypothesis for the reduced recurrence with chemical pleurodesis is that instilled agents may reach areas that are hard to reach with conventional instruments during thoracoscopy. ${ }^{10}$

The concept of utilizing a brush for pleurodesis is not a new one and was described in 1976, predating video-assisted thoracoscopy. ${ }^{12}$ In fact, an electric rotating brush has also been described, although it has not gained widespread popularity. ${ }^{6}$ A simpler variation of a rotating brush is the Pleurabrade (Butterfield Technologies) that was utilized in these two patients. It is a nylon bristle brush on a twisted stainless steel wire at the end of a stainless steel shaft. It can be bent to better contour to the curved pleural surfaces and can fit through a 5-mm port. Compared with other means of achieving pleural abrasion such as using a scratch pad or a sponge, the benefits of the Pleurabrade (Butterfield Technologies) for mechanical pleurodesis are that it is less likely to be left in the chest as a retained foreign body and that it can abrade the pleural surfaces more widely leading to a more efficient mechanical pleurodesis.

As is evident from the operative videos, the Pleurabrade (Butterfield Technologies) can be efficiently used to perform a mechanical pleurodesis in patients with primary spontaneous pneumothorax. Both patients in this series had no postoperative complications and are recurrence free. We believe this is a safe instrument in the arsenal of the thoracic surgeon managing primary spontaneous pneumothorax, although further studies need to be performed to document its safety profile, efficacy, and durability compared with other modalities ( - Video 1 ).

\section{Video 1}

Video showing the case presentations and operative usage of the Pleurabrade (Butterfield Technologies, Portland, Maine, United States). Online content including video sequences viewable at: https://www. thieme-connect.com/products/ejournals/html/ $10.1055 / \mathrm{s}-0041-1723950$

\section{Conclusion}

VATS mechanical pleurodesis by pleural abrasion as a treatment for primary spontaneous pneumothorax (particularly in recurrent cases or cases with high-risk features) can be thoroughly and efficiently accomplished using the 
Pleurabrade (Butterfield Technologies) as depicted in the operative video. The device reduces the risk of foreign body retention and can be better contoured than other abrasion techniques (such as using a scratch pad or sponge) to reach all the pleural surfaces. We believe it is a safe and effective instrument for mechanical pleurodesis, although further studies are needed.

\section{Conflict of Interest}

Dr. Bueno reports personal fees from Butterfield Technologies/Pleurabrade, during the conduct of the study; grants from $\mathrm{NCI}$, grants from NIBIB, grants from DOD, grants from Roche, grants from GeneTech, grants from Siemens, grants from Merck, grants from Verastem, grants from Gristone, grants from MedGenome, grants from Epizyme, other from Navigation Sciences, personal fees from Novocure, personal fees from Intuitive, outside the submitted work.

\section{References}

1 Melton LJ III, Hepper NG, Offord KP. Incidence of spontaneous pneumothorax in Olmsted County, Minnesota: 1950 to 1974. Am Rev Respir Dis 1979;120(06):1379-1382

2 MacDuff A, Arnold A, Harvey JBTS Pleural Disease Guideline Group. Management of spontaneous pneumothorax: British Thoracic Society Pleural Disease Guideline 2010. Thorax 2010;65 (Suppl 2):ii18-ii31
3 Brown SGA, Ball EL, Perrin K, et al;PSP Investigators. Conservative versus interventional treatment for spontaneous pneumothorax. N Engl J Med 2020;382(05):405-415

$4 \mathrm{Ng} \mathrm{C}$, Maier HT, Kocher F, et al. VATS partial pleurectomy versus VATS pleural abrasion: significant reduction in pneumothorax recurrence rates after pleurectomy. World J Surg 2018;42(10): 3256-3262

5 Coosemans W, Lerut TE, Van Raemdonck DE. Thoracoscopic surgery: the Belgian experience. Ann Thorac Surg 1993;56(03): 721-730

6 Maier A, Anegg U, Renner H, et al. Four-year experience with pleural abrasion using a rotating brush during video-assisted thoracoscopy. Surg Endosc 2000;14(01):75-78

7 Olesen WH, Katballe N, Sindby JE, et al. Surgical treatment versus conventional chest tube drainage in primary spontaneous pneumothorax: a randomized controlled trial. Eur J Cardiothorac Surg 2018;54(01):113-121

8 Rodriguez-Panadero F, Montes-Worboys A. Mechanisms of pleurodesis. Respiration 2012;83(02):91-98

9 Min X, Huang Y, Yang Y, et al. Mechanical pleurodesis does not reduce recurrence of spontaneous pneumothorax: a randomized trial. Ann Thorac Surg 2014;98(05):1790-1796, discussion 1796

10 Sim SKR, Nah SA, Loh AHP, Ong LY, Chen Y. Mechanical versus chemical pleurodesis after bullectomy for primary spontaneous pneumothorax: a systemic review and meta-analysis. Eur J Pediatr Surg 2019:s-0039-s-1697959

11 Gossot D, Galetta D, Stern JB, et al. Results of thoracoscopic pleural abrasion for primary spontaneous pneumothorax. Surg Endosc 2004;18(03):466-471

12 Kurzweg FT, Williamson JW, Daron PB, Danna SJ. Brush pleurodesis. Am Surg 1976;42(08):581 